\title{
Does varicocele correction lead to normalization of preoperatively elevated mean platelet volume levels?
}

\author{
Soner Coban, MD; Ibrahim Keles, MD; ${ }^{\dagger}$ ismail Biyik, MD; Muhammet Guzelsoy, MD;" Ali Riza Turkoglu, MD;* \\ Nihal Ocak, MD*
}

*Department of Urology, Şevket Yılmaz Training and Research Hospital, Bursa, Turkey; †'Department of Urology, School of Medicine, Afyon Kocatepe University, Afyonkarahisar, Turkey; §Department of Obstetrics and Gynecology, Karacabey State Hospital, Bursa, Turkey; *Department of Biochemistry, Şevket Yılmaz Training and Research Hospital, Bursa, Turkey.

Cite as: Can Urol Assoc J 2015;9(1-2):E5-9. http://dx.doi.org/10.5489/cuaj.2113

Published online January 12, 2015.

\section{Abstract}

Introduction: There are several studies on the relationship between increased mean platelet volume (MPV) and varicocele. We investigated the relationship between preoperative and 6-month postoperative MPV values in patients whose varicocele was corrected with surgery.

Methods: A total of 282 patients underwent surgery at our urology clinic between December 2011 and December 2013 for primary varicocele. We retrospectively examined the records of 61 patients who came to the 6-month postoperative follow-up. The preoperative varicocele diagnosis was made with physical examination findings and supported with colour Doppler ultrasonography.

Results: The varicocele was grade I in 12 patients, grade II in 34 patients and grade III in 11 patients. When the preoperative and 6-month postoperative haemoglobin (Hb), MPV, mean corpuscular volume, platelet, and platelet distribution width (PDW) values were compared, there was a significant decrease in MPV $(p=0.019)$, and a significant increase in $\mathrm{Hb}(p<0.001)$. A noticeable increase was also present in PDW, but it was not statistically significant $(p=0.058)$.

Conclusion: We found that MPV increased in patients with varicocele and tended to decrease again after the varicocele was surgically corrected. However, we feel larger prospective series are needed.

\section{Introduction}

Varicocele is defined as the dilatation of the pampiniform plexus of veins surrounding the testis. ${ }^{1}$ Clinical varicoceles are present in about $15 \%$ of the general male population, and in up to $35 \%$ of men with primary infertility and $75 \%$ of men with secondary infertility. ${ }^{2}$ Varicoceles that are diagnosed primarily via physical examination are referred to as clinical varicoceles, whereas those that are $<3 \mathrm{~mm}$ in diam- eter and observed only via colour Doppler ultrasonography (CDU) with the Valsalva maneuver are considered subclinical varicoceles. ${ }^{3}$ Varicoceles are associated with other vascular pathologies. ${ }^{4}$ Kılıç and colleagues also reported that peripheral varicose veins share a pathological mechanism with varicocele. ${ }^{5}$

Mean platelet volume (MPV) is a parameter provided by the automatic blood count device during a routine blood count, but clinicians do not usually pay it much attention. It has been associated with thrombocyte volume, function, and activation. ${ }^{6}$ MPV and platelet distribution width (PDW) are markers of platelet activation. ${ }^{7-9}$ It is generally accepted that thrombocyte volume is determined during the production of thrombocytes from megakaryocytes. ${ }^{10}$ It is believed that large thrombocytes are younger ${ }^{11}$ and less reactive. ${ }^{12}$ Increased MPV is associated with the presence and prognosis of vascular disease, including peripheral, cerebrovascular, and coronary artery disease..$^{13}$

Although there are studies on the relationship between MPV and vascular diseases, only a few investigate the relationship between MPV and varicocele. Coban and colleagues found that MPV values were higher in varicocele group than in the control group. ${ }^{14}$ Therefore, we designed this study to compare preoperative and postoperative MPV values in varicocele patients. We investigated the relationship between preoperative and 6-month postoperative MPV values in patients whose varicocele was corrected with surgery.

\section{Methods}

Of the 282 patients who underwent surgery at our Şevket Yılmaz Training and Research Hospital's Department of Urology between December 2011 and December 2013 due to primary varicocele, we retrospectively investigated the records of 61 patients at their 6-month follow-up. All patients underwent varicocelectomy with a standard inguinal approach. This study was approved by our insti- 
tutional review board. Only 1 patient had bilateral varicocele, while the others had a unilateral left varicocele. The indication for surgery was infertility (primary in 38 patients, secondary in 16 patients) in 54 patients and other factors (pain, cosmetic reasons, etc.) in 3 patients. We obtained the following information from patients: medical history, physical examination, CDU, platelet, MPV, PDW, hemoglobin, white blood cell (WBC), and mean corpuscular volume (MCV) values. The preoperative varicocele diagnosis was made by physical examination and supported with CDU. Varicocele was grouped as mild (grade I: varicose veins are palpable only during the Valsalva maneuver), moderate (grade II: varicose veins may be palpable during rest but not visible), or severe (grade III: visible varicose veins).

Cases with non-varicocele scrotal pathologies (e.g., undescended testis, testicular torsion, epididymitis, orchitis, epidimo-orchitis, inguinal hernia, testicular mass) or systemic disease (e.g., hematological disorder, hypertension, diabetes mellitus, chronic renal failure, collagen vascular disease) were excluded from the study.

The full blood count test was performed with an automatic blood count test device (Abbott Cell-Dyn 3700 hematology analyzer) using blood with K-EDTA (Potassium-ethylene diamine tetraacetic acid) anticoagulation at our hospital. We compared the preoperative and 6-month postoperative hemogram results.

Statistical tests were performed using software for Windows. Compliance of variables with a normal distribution was analyzed with visual (histogram and probability plots) and analytical methods (the Kolmogorov-Smirnov test). Descriptive analyses were provided as mean and standard deviation. Since the MPV and hemoglobin values showed normal distribution, the paired-t test was used in the preoperative and postoperative comparison of these parameters, while the Wilcoxon test was used for the other parameters that did not comply with the normal distribution. Statistical significance was set at $p<0.05$.

\section{Results}

The mean age of the patients was $28.93 \pm 0.87$ (range: 16-45) (Table 1). The varicocele was grade I in 12 patients, grade II in 34 patients and grade III in 11 patients, while the bilateral case was grade III on the left and grade I on the right. We excluded 4 patients with recurrence on CDU postoperatively. When the preoperative and 6-month postoperative hemoglobin, MPV, MCV, platelet, and PDW values were compared, there was a significant decrease in MPV $(p=0.019)$, and a significant increase in hemoglobin $(p<0.001)$. A noticeable increase was also present in PDW, but it was not statistically significant $(p=0.058)$. Preoperatively and postoperatively mean MPV, PDW, and hemoglobin values are illustrated (Fig. 1, Fig. 2, Fig. 3).

\begin{tabular}{|c|c|c|c|}
\hline & Preoperative & $\begin{array}{l}\text { Postoperative } \\
\text { at } 6 \text { months }\end{array}$ & $p$ value \\
\hline Age, years & $28.93 \pm 0.87$ & & \\
\hline Varicocele grade I & 12 & & \\
\hline Varicocele grade II & 34 & & \\
\hline Varicocele grade III & 11 & & \\
\hline Total patients & 57 & & \\
\hline MPV (fL) & $8.33 \pm 0.99$ & $8.10 \pm 1.09$ & 0.019 \\
\hline $\operatorname{PLT}(\times 103 \mu \mathrm{L})$ & $242.42 \pm 49.75$ & $244.84 \pm 55.66$ & 0.666 \\
\hline PDW (fL) & $16.88 \pm 2.07$ & $17.46 \pm 1.70$ & 0.058 \\
\hline $\mathrm{MCV}(\mathrm{fL})$ & $87.37 \pm 6.64$ & $87.10 \pm 5.11$ & 0.928 \\
\hline WBC $\left(\times 10^{3} \mu \mathrm{L}\right)$ & $7.03 \pm 2.12$ & $7.80 \pm 2.70$ & 0.056 \\
\hline $\mathrm{Hb}(\mathrm{g} / \mathrm{dL})$ & $14.40 \pm 1.13$ & $14.91 \pm 1.02$ & $<0.001$ \\
\hline
\end{tabular}

MPV: Mean platelet volume, PLT: Platelet, PDW: Platelet distribution width, MCV: Mean corpuscular volume, WBC; White blood cell, Hb: Hemoglobin.

\section{Discussion}

A varicocele is the most common correctable cause of male infertility and is defined as the abnormal dilatation of the veins creating the pampiniform plexus due to venous reflux. The usual etiological factors include hydrostatic pressure increase in the venous structures and venous reflux development due to anatomical features. The most important factors that can cause such a hydrostatic pressure increase is the compression of the left renal vein between the superior mesenteric artery and the aorta (nutcracker phenomenon), inadequate gonadal vein valves, and direct opening of the left testicular vein to the left renal vein. ${ }^{15}$

Although it is not known how a varicocele creates damage in the testis, there are many theories. The two common accepted theories in varicocele pathophysiology are testicular temperature increase and reflux of adrenal metabolits. Consequently varicocele can cause infertility via testicular damage, decrease of testicular volume, decrease of leydig cell functions, and impairment of spermatogenesis. ${ }^{16}$

A varicocele is a vascular problem. The cause is not definitely known although there are many theories on the physiopathogenesis. Vascular pathologies are associated with increased thrombocyte activity and increased thrombocyte volume. The increased thromboxan, serotonin, $\beta$-thromboglobulin, P-selectin, glycoprotein IIla secretion and the decreased prostacyclin secretion from these activated thrombocytes facilitate vasoconstriction and thrombocyte aggregation, leading to a high thrombotic potential. ${ }^{17-19}$ The changes in the thrombocyte volume indicators can therefore have prophylactic and diagnostic value in thrombotic and prethrombotic events. ${ }^{19}$

Elevated MPV values have been shown in atherothrombotic disorders, such as acute myocardial ischemia, acute myocardial infarction, coronary atherosclerosis, and cerebrovascu- 


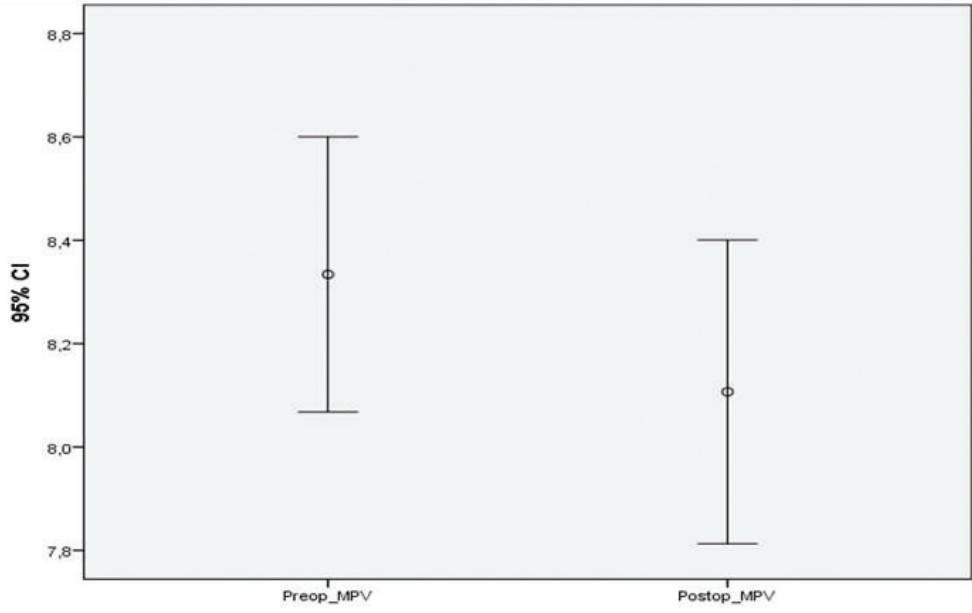

Fig. 1. The mean platelet volume (MPV) preoperative and 6-month postoperative values.

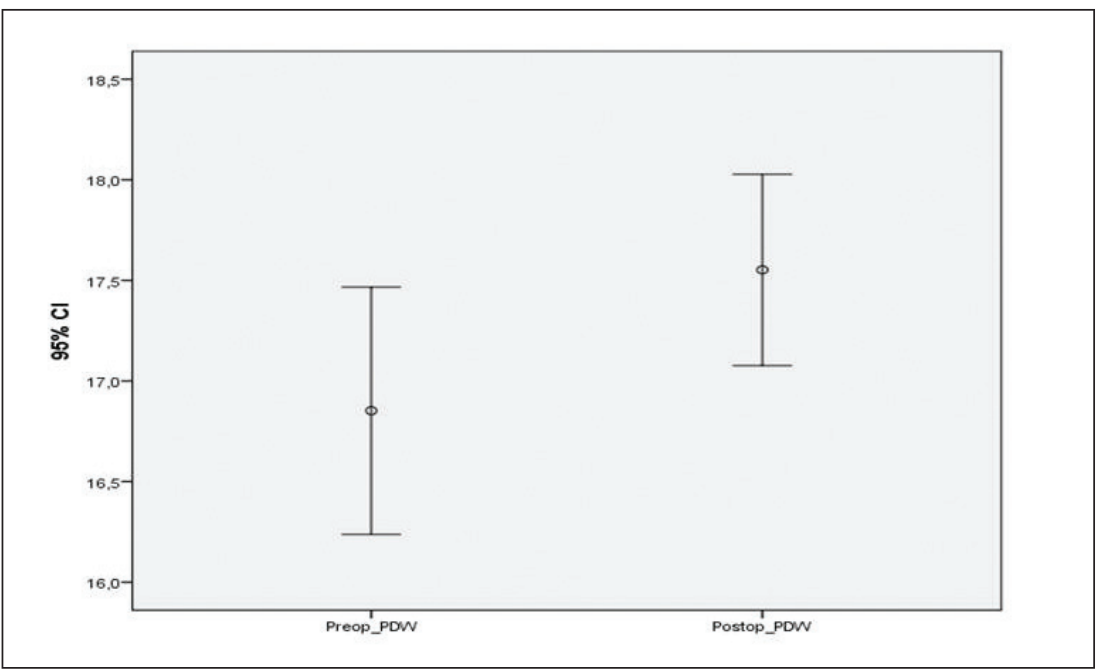

Fig. 2. The mean platelet distribution width (PDW) preoperative and 6-month postoperative values.

lar events. An increase in MPV has also been reported in conditions closely associated with insulin resistance, such as metabolic syndrome, obesity, diabetes mellitus, and hypertension. ${ }^{9}$ Çoban and colleagues found significantly higher MPV in obese patients with a body mass index of $\geq 30 \mathrm{~kg} / \mathrm{m}^{2}$ than in non-obese patients. ${ }^{20}$ They also reported that weight loss in obese people led to a significant decrease in MPV; this in turn decreased cardiovascular disease risk by an antiatherogenic effect and by suppressing thrombocyte activation. ${ }^{21}$ Kario and colleagues similarly found the thrombocyte count and MPV much higher in smoking patients and those with atherosclerotic lesions than in non-smoking patients and those with no atherosclerotic lesions and suggested that increased MPV accelerated atherosclerosis development. They also noticed a 10\% decrease in MPV 1 to 3 months after quitting smoking in the atherosclerotic group. ${ }^{22}$
There are only a few studies investigating the relationship between MPV and varicocele. Bozkurt and colleagues reported the MPV values in a varicocele group were significantly higher than in the control group; their study included 60 patients with varicocele and 57 control group patients. They also found a significant correlation between MPV and varicocele grade and left spermatic vein diameter. ${ }^{23} \mathrm{We}$ similarly evaluated the relationship between MPV and varicocele in 264 varicocele patients and 220 control subjects in another study and found MPV high in the patient group. However, we did not find a positive correlation between varicocele grade and left spermatic vein diameter. ${ }^{14}$ In the current continuation study, we investigated the relationship between preoperative and 6-month postoperative MPV values in patients whose varicoceles had been corrected with surgery. While a significant decrease was found in MPV 


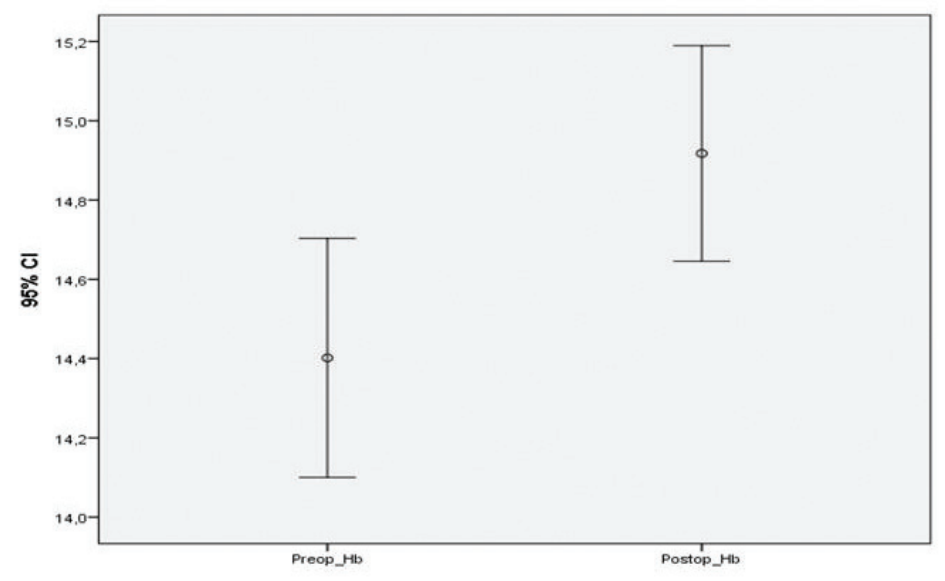

Fig. 3. The mean hemoglobin $(\mathrm{Hb})$ preoperative and 6-month postoperative values.

in the postoperative period, a noticeable rise was seen in PDW. However, we did not find a statistical significance. Studies evaluating the relationship between MPV and chronic inflammatory disease have shown high MPV values in patients with rheumatoid arthritis in the active period of the disease with high inflammatory marker levels. ${ }^{24}$ Similarly, MPV values decreased after treatment of active disease in patients with ankylosing spondylitis. ${ }^{25}$

Furthermore, higher MPV values were shown in patients with severe obstructive sleep apnea leading to cardiovascular complications compared to a control group in a study with 95 subjects. ${ }^{26} \mathrm{~A}$ significant decrease was found in MPV after continuous positive airway pressure (CPAP) treatment for 6 months in a similar group of patients. ${ }^{27}$

We found lower hemoglobin levels in the varicocele group compared to controls. Some studies have reported lower testosterone levels in varicocele patients. ${ }^{28}$ Ferrucci and colleagues reported that men in the lowest quartile of total and bioavailable testosterone were more likely to have anemia. ${ }^{29}$ Although we did not study serum testosterone levels in this study, the lower hemoglobin in the varicocele group could be associated with low testosterone levels.

\section{Conclusion}

MPV is widely used to measure platelets. It increases in patients with varicocele and tends to decrease again in patients whose varicocele is corrected with surgery. Although we found that varicocele surgery corrected preoperatively increased MPV levels in this study, further larger series are need to support to this finding.

Competing interests: Authors declare no competing financial or personal interests.
This paper has been peer-reviewed.

\section{References}

1. Jarow JP, Espeland MA, Lipshultz LI. Evaluation of the azoospermic patient. J Urol 1989;142:62-5.

2. Goldstein M. Surgical management of male infertility. In: PCBs: Campbell-Walsh Urology. 10th edition. Wein A, Kavoussi LR, Novick AC, Partin AW, Peters CA, editors. Philadelphia, PA: Elsevier Saunders; 2012:648-87. http://dx.doi.org/10.1016/B978-1-4160-6911-9.00022-0

3. Inci K, Gunay LM. The role of varicocele treatment in the management of non-obstructive azoospermia. Clinics 2013;68:89-98. http://dx.doi.org/10.6061/dinics/2013(Sup01) 10

4. Yetkin E, Kilic S, Acikgoz N, et al. Increased prevalence of varicocele in patients with coronary artery ectasia. Coron Artery Dis 2005;16:261-4. http://dx.doi.org/10.1097/00019501-200508000-00001

5. Kilic S, Aksoy Y, Sincer I, et al. Cardiovascular evaluation of young patients with varicocele. Fertil Steril 2007;88:369-73. http://dx.doi.org/10.1016/ifertnstert.2006.11.119

6. Bath PM, Butterworth RJ. Platelet size: Measurement, physiology and vascular disease. Blood Coagul Fibrinolysis 1996;7:157-61. http://dx.doi.org/10.1097/00001721-199603000-00011

7. Jagroop IA, Clatworthy I, Lewin J, et al. Shape change in human platelets: Measurement with a channelyzer and visualisation by electron microscopy. Platelets 2000;11:28-32. http://dx.doi. org/10.1080/09537100075760

8. Park Y, Schoene N, Harris W. Mean platelet volume as an indicator of platelet activation: Methodological issues. Platelets 2002;13:301-6. http://dx.doi.org/10.1080/095371002220148332

9. Gasparyan AY, Ayvazyan L, Mikhailidis DP, et al. Mean platelet volume: A link between thrombosis and inflammation? Curr Pharm Des 2011;17:47-58. http://dx.doi.org/10.2174/138161211795049804

10. Martin J. The relationship between megakaryocyte ploidy and platelet volume. Blood Cells 1989;15:10817.

11. Chatterii AK, Lynch EC, Garg SK, et al. Circulating large platelets. N Engl J Med 1971;284:1440-1. http://dx.doi.org/10.1056/NEJM197106242842517

12. Van der Loo B, Martin JF. Megakaryocytes and platelets in vascular disease. Baillieres Clin Haematol 1997;10:109-23. http://dx.doi.org/10.1016/S0950-3536(97)80053-4

13. Vizioli L, Muscari S, Muscari A. The relationship of mean platelet volume with the risk and prognosis of cardiovascular diseases. Int J Clin Pract 2009;63:1509-15. http://dx.doi.org/10.1111/i.17421241.2009.02070.x

14. Coban S, Keleş I, Biylk I, et al. Is there any relationship between mean platelet volume and varicocele? Andrologia Jan 6. 2014. http://dx.doi.org/10.1111/and.12220

15. Kendirci M, Miroğlu C. Erkek Reprodüktif Sistem Hastallkları ve Tedavisi. Varikosel Patofizyolojisi, ed. Türk Androloii Derneği Yayinlarn, İstanbul; 2004:427-46.

16. World Health Organization. The influence of varicocele on parameters of ferrility in a large group of men presenting to infertility clinics. Fertil Steril 1992;57:1289-93.

17. Rao AK, Goldberg RE, Walsh PN. Platelet coagulation activities in diabetes mellitus. Evidence for relationship between platelet coagulant hyperactivity and platelet volume. J Lab Clin Med 1984;103:82-92. 
18. Mathur A, Robinson MS, Cotton J, et al. Platelet reactivity in acute coronary syndromes. Evidence for differences in platelet behaviour between unstble angina and myocardial infarction. Thromb Haemost 2001;85:989-94.

19. Martin JF, Bath PM, Burr ML. Influence of platelet size on out-come after myocardial infarction. Lancet 1991;338:1409-11. http://dx.doi.org/10.1016/0140-6736(91)92719-1

20. Coban $E$, Özdoğan M, Yazıcıoğlu $G$, et al. The mean platelet volume in patients with obesity. Int I Clin Prac 2005;59:981-2. http://dx.doi.org/10.1111/.1.1742-1241.2005.00500.x

21. Coban E, Yılmaz A, Sarı R. The effect of weight loss on the mean platelet volume in obese patients. Platelets 2007;18:212-6. http://dx.doi.org/10.1080/09537100600975362

22. Kario K, Matsuo T, Nakao K. Cigarette smoking increases the mean platelet volume in elderly patients with risk factors for atherosclerosis. Clin Lab Haematol 1992;14:281-7. http://dx.doi. org/10.1111/i.1365-2257.1992.tb00103.x

23. Bozkurt Y, Soylemez H, Sancaktutar AA, et al. Relationship between mean platelet volume and varicocele: A preliminary study. Urology 2012;79:1048-51. http://dx.doi.org/10.1016/i.urology.2012.01.019

24. Milovanovic M, Nilsson E, Järemo P. Relationships between platelets and inflammatory markers in rheumatoid arthritis. Clin Chim Acta 2010;343:237-40. http://dx.doi.org/10.1016/i.cccn.2003.12.030
25. Yazici $S$, Yazici $M$, Erer $B$, et al. The platelet functions in patients with ankylosing spondylitis: anti-TNFalpha therapy decreases the mean platelet volume and platelet mass. Platelets 2010;21:126-31. http:// dx.doi.org/10.3109/09537100903470306

26. Varol E, Ozturk 0, Gonca T, et al. Mean platelet volume is increased in patients with severe obstructive sleep apnea. Scand I Clin Lab Invest 2010;70:497-502. http://dx.doi.org/10.3109/00365513.2 010.520733

27. Varol E, Ozturk 0, Yucel $H$, et al. The effects of continuous positive airway pressure therapy on mean platelet volume in patients with obstructive sleep apnea. Platelets 201 1;22:552-6. http://dx.doi.org/ 10.3109/09537104.2011.578182

28. Tanrikut C, Goldstein M, Rosoff IS, et al. Varicocele as a risk factor for androgen deficiency and effect of repair. BJU Int 2011;108:1480-4. http://dx.doi.org/10.1111/i.1464-410X.2010.10030.x

29. Ferrucci L, Maggio M, Bandinelli S, et al. Low testosterone levels and the risk of anemia in older men and women. Arch Intern Med 2006;166:1380-8. http://dx.doi.org/10.1001/archinte.166.13.1380

Correspondence: Dr. İsmail Biyik, Tavsanli Street 56 Road No:4 16700 Karacabey/Bursa, Turkey; dribiyik@hotmail.com 